\title{
Clipping a gastric lesion before resection: not a contraindication for endoscopic submucosal dissection
}
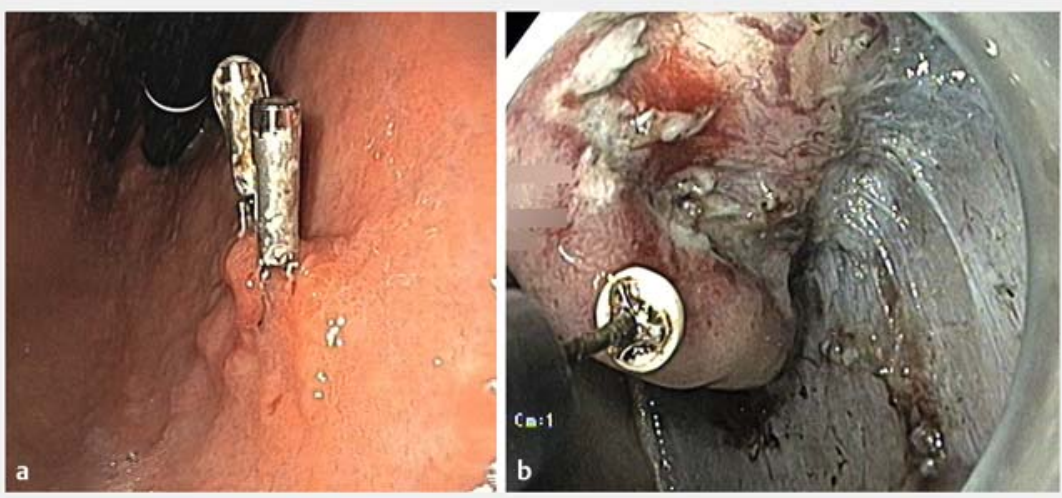

Fig. 1 Endoscopic views showing: a a type 0-lla lesion in the lesser curvature of the corpus with two metal clips that were placed during a diagnostic procedure; $\mathbf{b}$ submucosal fibrosis noticed within the clipped area during the endoscopic submucosal dissection procedure.
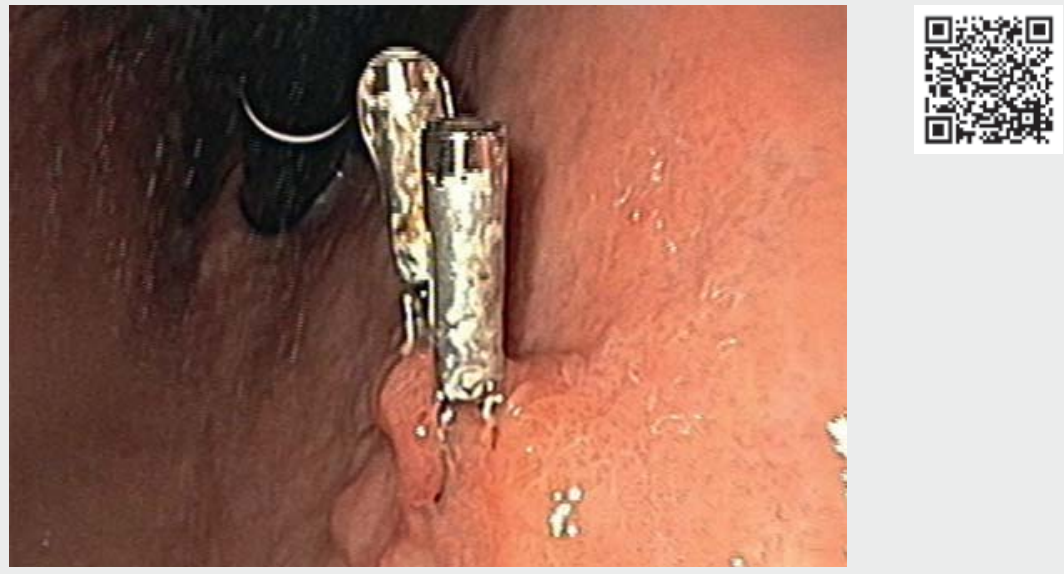

$\checkmark$ Video 1 A 0-Ila lesion with two metal clips placed during the diagnostic procedure was removed by endoscopic submucosal dissection. Submucosal fibrosis within the clipped area was noticed, but en bloc resection was achieved without complications.

A 53-year-old woman underwent an upper gastrointestinal endoscopy because of dyspepsia. A 15-mm, type 0 -Ila lesion was identified in the lesser curvature of the distal corpus. After a biopsy was taken, a moderate hemorrhage occurred and two metal clips were applied ( Fig.1a). The histopathological result showed high grade dysplasia so the pa- tient was referred to our department to undergo endoscopic resection.

After proper multidisciplinary discussion and clear information on the expected technical challenges, endoscopic submucosal dissection (ESD) was planned and then performed using an insulatedtip knife (IT-knife 2; Olympus), with the patient under deep sedation. First, sub-

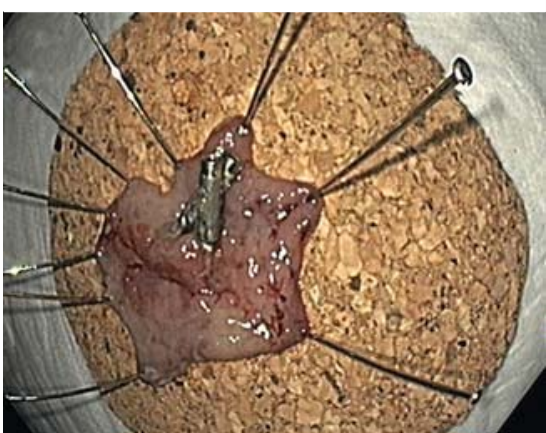

Fig. 2 Macroscopic appearance of the en bloc resected specimen.

mucosal injection and circumferential incision were performed and ESD was then completed from the distal to the proximal side. Although submucosal fibrosis was noticed within the clipped area ( $>$ Fig. $\mathbf{1 b}$ ), en bloc resection was achieved without adverse events ( $\vee$ Fig. 2; V Video 1). At the end of ESD, major vessels in the scar were prophylactically coagulated (Coagrasper Hemostatic Forceps; Olympus). No delayed complications were observed and the patient was discharged after 3 days. Histopathological analysis revealed a moderately differentiated adenocarcinoma with superficial submucosal invasion $(<0.5 \mathrm{~mm})$, without lymphovascular or perineural invasion, and with negative vertical/horizontal margins ( $\mathbf{F i g . 3}$ ).

Risk factors for difficult ESD of gastric lesions include larger size, middle- or upper-third location, and the presence of ulceration, submucosal fibrosis, or invasive cancer [1-3]. The technical implications of the presence of a clip within a gastric lesion have not been fully studied, but it is likely to add a degree of difficulty because of a fibrotic reaction in the submucosal layer and the potential risk of thermal injury by cutting adjacent to the clip.

We consider that ESD of lesions carrying a metal clip may be a feasible and safe and that this should not be considered 


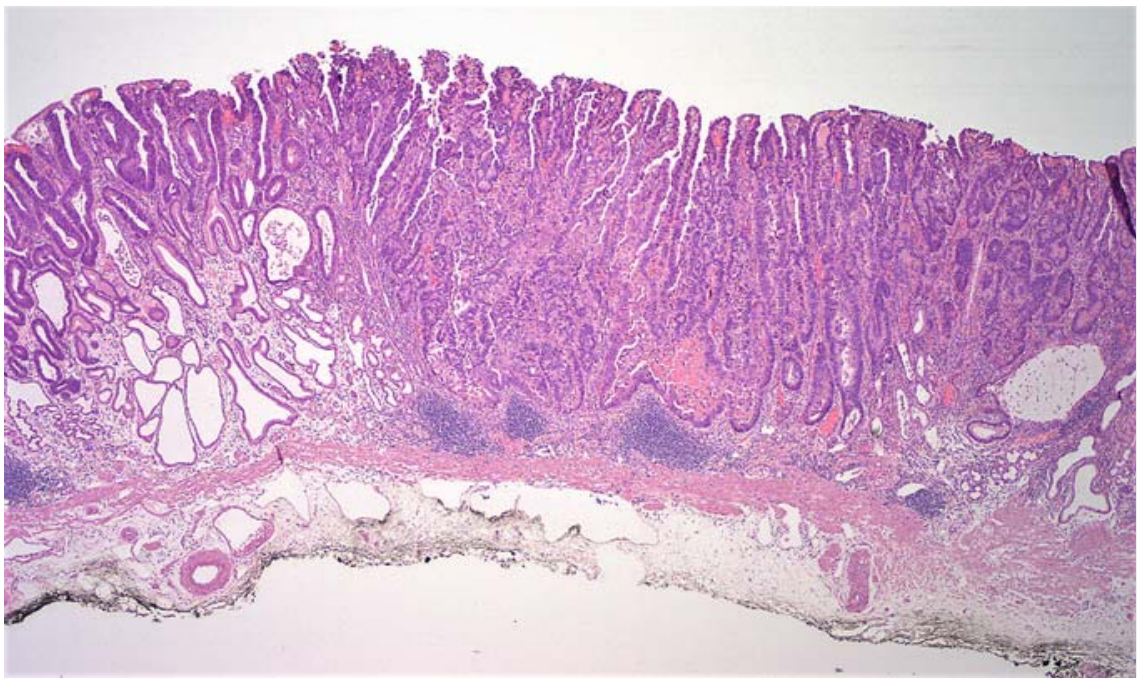

- Fig. 3 Histopathological view showing a moderately differentiated adenocarcinoma with superficial submucosal invasion, without lymphovascular/perineural invasion, and with negative vertical/horizontal margins.

a contraindication for endoscopic management.

\section{Endoscopy_UCTN_Code_TTT_1AO_2AG}

\section{Competing interests}

The authors declare that they have no conflict of interest.

The authors

\section{Marta Rodríguez-Carrasco', Madalena Souto Moura², Ana Luísa Cunha², Mário Dinis- Ribeiro $^{1,3}$}

1 Gastroenterology Department, Portuguese Oncology Institute of Porto, Portugal

2 Pathology Department, Portuguese Oncology Institute of Porto, Portugal

3 MEDCIDS - Department of Community Medicine, Information and Decision in Health, Faculty of Porto, University of Medicine, Porto, Portugal

\section{Corresponding author}

\section{Marta Rodríguez-Carrasco, MD}

Gastroenterology Department, Portuguese Oncology Institute of Porto, Rua Dr. Bernardino de Almeida, 4200-072 Porto, Portugal

Fax: +351-22-5513646

martarc7@gmail.com

\section{References}

[1] Kim JH, Nam HS, Choi CW et al. Risk factors associated with difficult gastric endoscopic submucosal dissection: predicting difficult ESD. Surg Endosc 2017; 31: 1617-1626

[2] Imagawa A, Okada H, Kawahara Y et al. Endoscopic submucosal dissection for early gastric cancer: results and degrees of technical difficulty as well as success. Endoscopy 2006; 38: 987-990

[3] Nagata S, Jin Y-F, Tomoeda M et al. Influential factors in procedure time of endoscopic submucosal dissection for gastric cancer with fibrotic change. Dig Endosc 2011; 23 : 296-301

\section{Bibliography}

Endoscopy 2021; 53: E405-E406

DOI 10.1055/a-1308-0814

ISSN 0013-726X

published online 17.12 .2020

(c) 2020. Thieme. All rights reserved.

Georg Thieme Verlag KG, Rüdigerstraße 14,

70469 Stuttgart, Germany

ENDOSCOPY E-VIDEOS

https:/|eref.thieme.de/e-videos

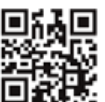

Endoscopy E-Videos is a free access online section, reporting on interesting cases and new techniques in gastroenterological endoscopy. All papers include a high quality video and all contributions are freely accessible online.

This section has its own submission website at https://mc.manuscriptcentral.com/e-videos 